\title{
Comunicação
}

[Communication]

\section{Tratamento alternativo em gatos acometidos por DITUIF}

[Alternative treatment in cats affected by FLUTD]

\author{
L.F.A. Trevisan ${ }^{1}$, R.V. Sousa ${ }^{1}$, S.K.V. Bertolucci ${ }^{1}$, O.G. Rodrigues ${ }^{2}$ \\ ${ }^{1}$ Programa de pós-graduação - UFLA - Lavras, MG \\ ${ }^{2}$ Unidade Acadêmica de Medicina Veterinária - UAMV - CSTR - UFCG
}

\begin{abstract}
A DITUIF, doença idiopática do trato urinário inferior felino, é um dos principais motivos para que proprietários de felinos procurem cuidados veterinários. Gatos com qualquer afecção no trato urinário inferior apresentam sinais clínicos semelhantes, como hematúria, polaciúria, estrangúria, postura de micção constante e/ou obstrução uretral (Dorsch et al., 2014).
\end{abstract}

O objetivo imediato do tratamento é a desobstrução; caso não haja obstrução, é o alívio da dor até que seja eliminada a sua causa. Analgésicos e espasmolíticos são administrados para prevenir o choque e a síncope resultante da dor intensa. A não ser que o paciente esteja vomitando, deve-se estimulá-lo a ingerir líquido, pois essa conduta tende a aumentar a pressão hidrostática. Essa ingestão alta de líquidos, dia e noite, reduz a concentração de cristaloides urinários e assegura um alto débito urinário (Norsworthy et al., 2010).

No Brasil, não existem muitos dados publicados sobre a incidência de desordens urinárias em felinos, mas Camargo (2004) apresentou dados nos quais dos 774 cães e gatos atendidos no período de 1999 a 2003 pelo Serviço de Nefrologia e Urologia do Hospital Veterinário "Governador Laudo Natel", da FCAV - Unesp de Jaboticabal, 107 eram de urolitíase (13,82\%), demonstrando elevada morbidade poporcional.

Em estudo realizado com felinos no Canadian Veterinary Urolith Center, mais de 22.000 casos foram analisados durante cinco anos. Destes, $4866(22,12 \%)$ diagnósticos foram de urolitíase vesical em gatos, e 618 (2,8\%) de plugs uretrais.
Aproximadamente $50 \%$ dos urólitos submetidos eram de oxalato de cálcio e $44 \%$ de estruvita (Houston et al., 2003). A formação de urólitos de estruvita foi mais comum em gatos jovens e adultos (um a sete anos); já gatos idosos (sete a nove anos) apresentaram maior tendência para formar cálculos de oxalato de cálcio. Em razão disso, as características das dietas devem variar para estas diferentes faixas etárias (Allen e Kruger, 2000).

Assim como na doença urinária felina, na grande maioria dos pacientes humanos a etiologia da inflamação das vias urinárias é desconhecida (Ratner, 2001). Em ambos os casos, ocorre uma diminuição da excreção renal de glicosaminoglicana e alteração na permeabilidade epitelial da bexiga (Buffington e Chew, 1996).

Nos poucos trabalhos em que a análise histopatológica da bexiga de gatos com DITUI foi realizada, observou-se um quadro histológico bastante semelhante ao da CI, ou seja, pronunciado edema da lâmina própria, infiltrado inflamatório mononuclear, aumento no número de mastócitos na mucosa vesical, pregueamento epitelial, petéquias subepiteliais e inflamação perineural (Reche Jr. e Hagiwara, 2001).

A presente comunicação apresenta um protocolo de tratamento alternativo de dois pacientes acometidos por DITUIF, utilizando-se o extrato de flores de Dianthus caryophyllus Linnaeus, que proporcionou a eliminação dos cálculos e a consequente recuperação da integridade do sistema urinário dos pacientes. 
O primeiro caso era um felino, macho, dois anos e seis meses, sem raça definida, pelagem preta, cujo proprietário procurou o $\mathrm{HV}$ com queixa de que o animal estava sem urinar a aproximadamente quatro dias.

Ao exame físico, observou-se disúria extremamente dolorosa e presença de grande volume na vesícula urinária.

O paciente foi submetido a um procedimento pré-anestésico, com acepromazina $(0,2 \mathrm{mg} / \mathrm{kg})$ e diazepam $(1 \mathrm{mg} / \mathrm{kg})$ por via intravenosa, e, logo após, anestesia epidural com cloridrato de lidocaína $(4 \mathrm{mg} / \mathrm{kg})$ associado a cetamina $(2,5 \mathrm{mg} / \mathrm{kg})$, com a finalidade de realizar a sondagem uretral seguida pela lavagem por urohidropropulsão com solução fisiológica e esvaziamento da vesícula urinária. O paciente foi submetido ao protocolo utilizado padrão para o tratamento da DITUIF, composto por: cloridrato de amitriptilina, $1 / 3$ de comprimido, $25 \mathrm{mg} / 24 \mathrm{~h}$, VO; glicosaminoglicano $100 \mathrm{mg} / 24 \mathrm{~h}, \mathrm{VO}$; agemoxi (amoxicilina tri-hidratada 1,5\%, Agener União, Brasil) $0,5 \mathrm{~mL} / 24 \mathrm{~h}, \mathrm{SC}$ e cetoprofeno $4 \mathrm{mg} / 24 \mathrm{~h}, \mathrm{SC}$.

Após 22 dias sem haver relato da extensão do tratamento, o paciente retornou com uma recidiva, agravada pela presença de gotas de sangue vivo que escoavam pelo pênis quando este tentava, sem sucesso, urinar, sendo encaminhado a cirurgia para realização dos procedimentos de cistotomia, para retirada dos cálculos, e subsequente penectomia.

Quinze dias após a cirurgia, o paciente apresentou nova recidiva e foi levado a outra clínica particular, onde foi tratado com antibioticoterapia, cuja agente antimicrobiano não foi relatado, e sondagem uretral seguida pela lavagem por uro-hidropropulsão repetidas vezes, até que foi recomendada sua eutanásia, ocasião na qual o proprietário retornou ao hospital veterinário, onde foi sugerido o tratamento alternativo com o novo fitoterápico.

Imediatamente, o paciente foi avaliado por palpação e foi constatado grande volume na vesícula urinária e espessamento de parede. Observou-se que ele tomava incessantemente posição de micção, sem sucesso, eliminando apenas gotículas de sangue.
Foram administrados, por sonda nasoesofágica, $150 \mathrm{mg}$ do extrato seco de flores de $D$. caryophyllus, diluídos em $40 \mathrm{~mL}$ de água; após 15 minutos, mais $75 \mathrm{mg}$ do extrato, diluídos em $20 \mathrm{~mL}$ de água. Vinte e cinco minutos após a primeira aplicação, o animal urinou normalmente em grande quantidade. A urina tinha coloração acastanhada, com presença de alguns cálculos, reconhecidos no exame de sedimento urinário como sendo cristais de uratos amorfos e cristais de ácido úrico (Fig. 1 e 2). Devido à presença excessiva de sangue, não foi possível realizar urinálise. Após 15 dias, o paciente sofreu outra recidiva e foi submetido ao mesmo protocolo com o extrato fitoterápico. Em 23 minutos, voltou a urinar; dessa vez, a urina apresentava odor e cor sui generis.

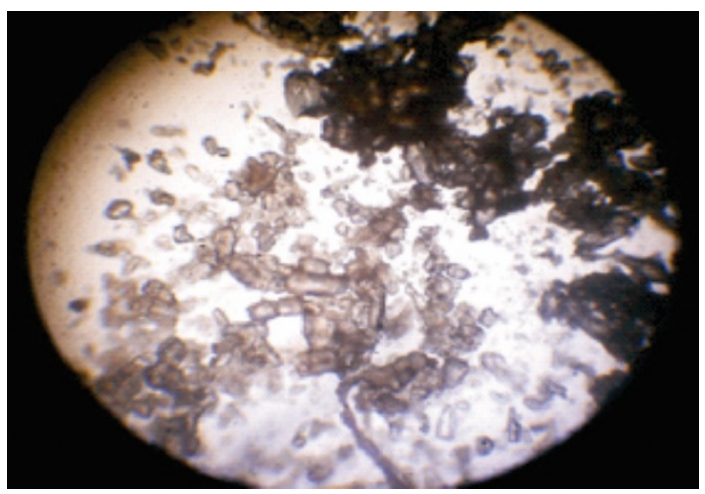

Figura 1. Gato. Cálculo vesical expelido por felino (40x).

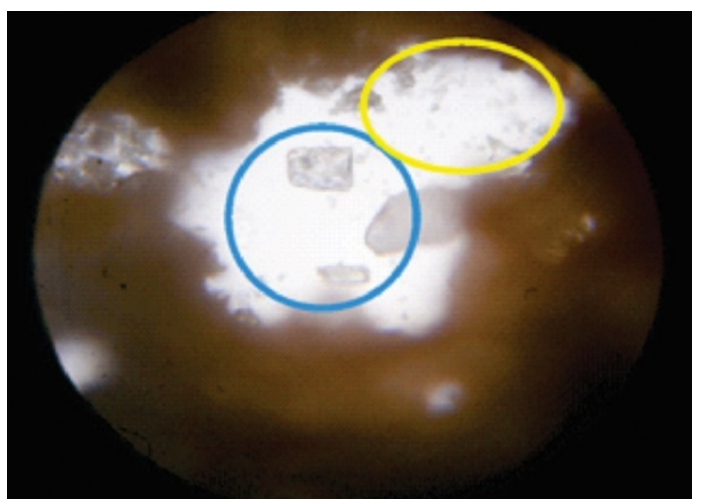

Figura 2. Gato. Esfregaço de urólito (40x): cristais de uratos amorfos (azul) e cristais de ácido úrico (amarelo).

Em nenhuma das ocasiões o paciente apresentou alterações nos índices séricos de ureia e creatinina. Ele foi acompanhado por um ano após o tratamento, não havendo, nesse período de histórico, novas recidivas. 
O segundo caso relatado envolveu um felino, macho, quatro anos, sem raça definida, pelagem preta e castanha, com histórico de ausência de micção há três dias.

Ao exame clínico, constatou-se que o paciente se apresentava com disúria dolorosa e sanguinolenta, apático e possuía alguns sintomas de intoxicação (midríase, salivação, incoordenação motora e presença de grunhidos constantes), levando a crer que estava entrando em quadro de uremia. À palpação, constatou-se presença de grande volume na vesícula urinária.

Foi relatado que o animal nunca havia estado doente antes, não havendo histórico de qualquer desordem em seu trato urinário, tampouco tinha sido submetido a tratamento anterior.

Foi sugerido ao proprietário o tratamento alternativo com o novo fitoterápico, o que foi aceito sem ressalvas.

Foram coletados $3 \mathrm{~mL}$ de sangue para análise bioquímica, constatando-se altos índices de ureia e creatinina sérica (Tab. 1).

Tabela 1. Bioquímica sérica de ureia e creatinina de gato

\begin{tabular}{lcc}
\hline & $\begin{array}{c}\text { Valores de } \\
\text { referência* }\end{array}$ \\
\hline Ureia - mg/dL & 100,3 & $10-30$ \\
Creatinina - & 2,2 & $0,8-1,8$ \\
$\mathrm{mg} / \mathrm{dL}$ & &
\end{tabular}

*Valores de referência segundo Hermes Pardini (2005).
Foram administrados, por sonda nasoesofágica, $150 \mathrm{mg}$ do extrato, diluídos em $40 \mathrm{~mL}$ de água e, após 15 minutos, mais $75 \mathrm{mg}$ do extrato, diluído em 20mL de água. Trinta minutos após a primeira aplicação, o animal tomou postura de micção, mas esta continuava obstruída, então se adotou, com sucesso, técnica de massagem na vesícula urinária com o intuito de auxiliar o animal em sua micção.

Juntamente a urina, que apresentava intensa hematúria e cor acastanhada, foram expelidos dois cálculos, medindo aproximadamente 2 e $3 \mathrm{~mm}$ de diâmetro, respectivamente, os quais, submetidos a esfregaço e analisados em microscopia óptica, foram identificados como cálculos de estruvita (fosfato de amônio magnesiano), muitas vezes erroneamente chamados de cristais de triplo fosfato ou fosfato triplo.

Duas horas após o esvaziamento da vesícula, coletou-se novamente urina, que tinha cor e odor sui generis, a qual foi levada para realização de urinálise com análise de sedimento.

O resultado da urinálise foi indicativo de DITUIF, e foi encontrado sangue oculto, sugerindo já haver lesão nas estruturas urinárias, traços de proteína e bilirrubina, que são indicativos de falha na filtração glomerular (Tab. 2), além de incontáveis cristais de estruvita (Fig. 3 e 4), confirmando o diagnóstico de urolitíase.

Tabela 2. Urinálise de gato doméstico após micção induzida pelo extrato de $D$. caryophyllus

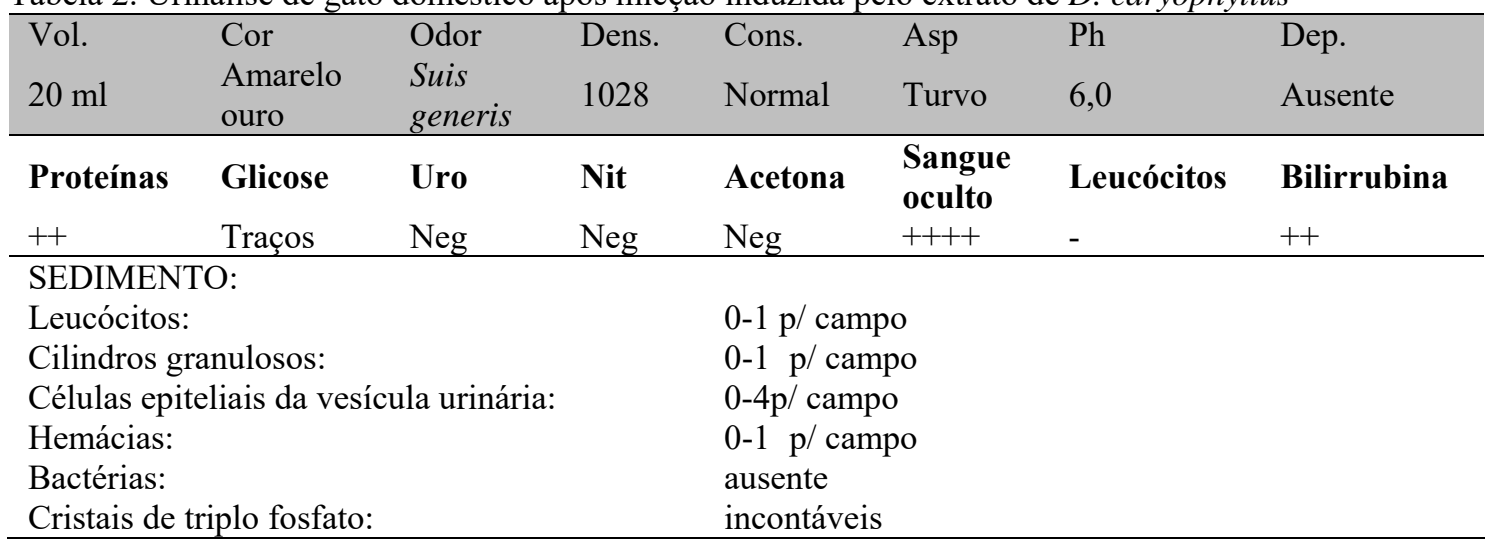


O paciente foi acompanhado por 11 meses, nos quais não houve relato de recidiva.

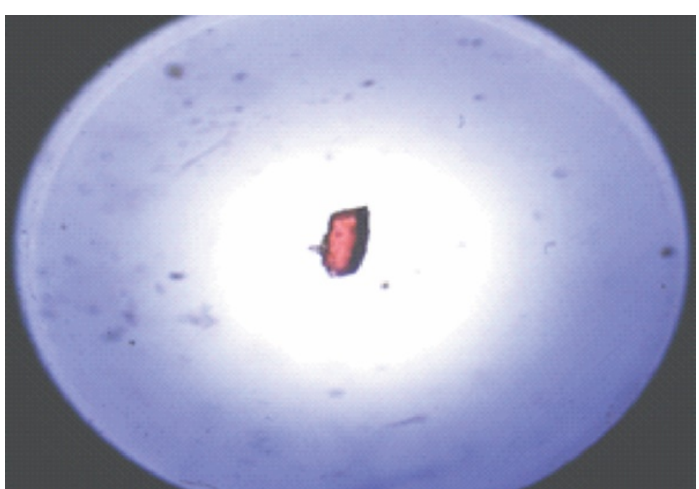

Figura 3. Gato. Cálculo de estruvita (20x) (fosfato de amônio magnesiano).

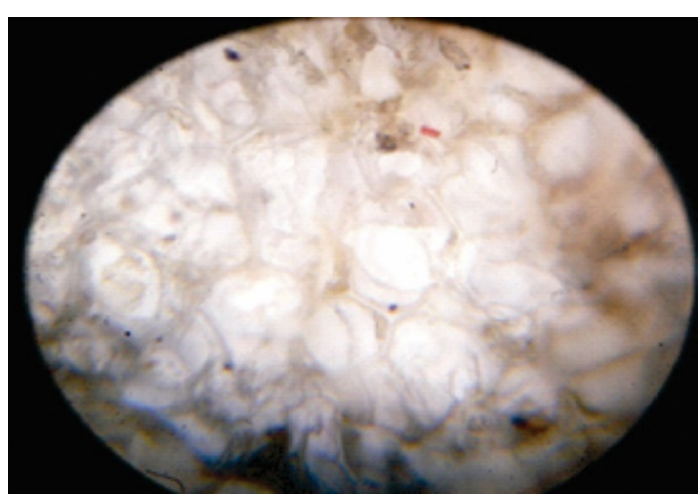

Figura 4. Gato. Cálculos de estruvita (fosfato de amônio magnesiano) (40x), obtidos em exame de sedimentoscopia de urina após tratamento com protocolo fitoterápico.

Em relação aos protocolos anteriormente aplicados nos pacientes, Norsworthy et al. (2010) recomendam que gatos com obstrução uretral devem ser submetidos à cateterização, tão logo seja possível, salientando que a repetida irrigação da bexiga com soluções isotônicas ajuda a remover os cristais da bexiga e que a administração de soluções alcalinizantes por via intravenosa pode ser realizada. A cistocentese é realizada quando a cateterização se torna difícil, e a administração de fenoxibenzamina por via oral tem se revelado uma medicação vantajosa para relaxamento da musculatura lisa da uretra. A urestrostomia perineal é indicada quando ocorrerem repetidas obstruções e também quando não for possível aliviar a obstrução uretral, devido à estenose uretral grave ou à presença de urólitos uretral.

No presente estudo, conseguiu-se identificar que extrato de $D$. caryophyllus apresenta em sua composição uma ampla taxa de peptídeos cíclicos e flavonoides glicosídicos, o que é corroborado por Condie et al. (2011) e Galeotti et al. (2008), respectivamente. A suposição é a de que o efeito antiurolítico apresentado pelo extrato se dá pela dilatação das estruturas urinárias de modo semelhante ao observado por este grupo de pesquisa com o mesmo produto sendo testado em ratos induzidos à hipertensão arterial (Trevisan, 2012).

Diferentemente do extrato de flores de $D$. caryophyllus, os protocolos indicados não se mostram eficazes no combate à doença, são invasivos, submetem o animal a medicamentos alopáticos de alto risco (piscotrópicos) e a suas várias reações adversas, além de não prevenirem contra recidivas.

Conclui-se que o efeito do extrato de flores de $D$. caryophyllus, nos animais gravemente acometidos, foi satisfatório, devido a sua rapidez e eficiência. Ainda, o extrato se mostrou eficiente no combate à DITUIF, por trazer resultados significativamente melhores que as abordagens tradicionais, sejam elas cirúrgicas ou terapêuticas.

Palavras-chave: DITUIF, Dianthus caryophyllus, urolitíase, fitoterapia

\section{ABSTRACT}

This report describes two cases of male cats affected by FLUTD (Feline lower urinary tract disease). The first patient had been affected by numerous relapses after passing through various therapeutic treatments and surgical interventions, and was subjected to the alternative protocol after being recommended for euthanasia, the second patient had no history of urinary tract disorders in the past, and was not subjected to any kind of previous treatment. The two patients had a significant improvement in their clinical condition, were not affected by relapses after participation in the alternative design, and were accompanied for about a year after their treatment.

Keywords: FLUTD, Dianthus caryophyllus, urolithiasis, phytotherapy 


\section{REFERÊNCIAS}

ALLEN, T.A.; KRUGER, J.M. Feline lower urinary tract disease. In: HAND, M.S.; THATCHER, C.D.; REMILLARD, R.L. et al. (Eds.). Small animal clinical nutrition. Kansas: Mark Morris Institute, 2000. p.589-723.

BUFFINGTON, C.A.; CHEW, D.J. Intermitent alkaline urine in a cat fed an acidifying diet. $J$. Am. Vet. Med. Assoc., v.209, p.103-104, 1996.

CAMARGO, C.P. Aspectos clínicos e epidemiológicos de urolitíases em cães e gatos assistidos pelo serviço de nefrologia e urologia da UNESP de Jaboticabal. 2004. 62f. Dissertação (Mestrado em Medicina Veterinária) - Faculdade de Ciências Agrárias e Veterinárias, Universidade Estadual Paulista, Jaboticabal, SP.

CONDIE, J.A; NOWAK, G.; REED, D.W. et al. The biosynthesis of Caryophyllaceae-like cyclic peptides in saponaria vaccaria L. from DNAencoded precursors. Plant J., v.67, p.682-690, 2011.

DORSCH, R.; REMER, C.; SAUTER-LOUIS, C.; HARTMANN, K. Feline lower urinary tract disease in a German cat population: a retrospective analysis of demographic data, causes and clinical signs. Tierarztl. Prax. Ausg. K Kleintiere Heimtiere, v.42, p.231-239, 2014.
GALEOTTI, F.; BARILE, E.; CURIR, P. et al. Flavonoids from carnation (Dianthus caryophyllus) and their antifungal activity. Phytochem. Lett., v.1, p.44-48, 2008.

HOUSTON, D.M.; MOORE, A.E.P.; FAVRIN, M.G.; HOFF, B. Feline urethral plugs and bladder urolithiasis: a review of 5484 submissions 1998-2003. Can. Vet. J., v.44, p.974-977, 2003.

MANUAL de exames. Belo Horizonte: Hermes Pardini, 2005. $160 \mathrm{p}$.

NORSWORTHY, G.D.; CRYSTAL, M.A.; GRACE, S.F.; TILLEY, L.P. The feline patient. Iowa: Wiley-Blackwell, 2010. 1072p.

RATNER, V. Interstitial cystitis: a chronic inflammatory bladder condition. World J. Urol., v.19, p.157-159, 2001.

RECHE JR, A.; HAGIWARA, M.K. Histopatologia e morfometria da bexiga de gatos com doença idiopática do trato urinário inferior (DITUI). Ciênc. Rural, v.31, p.1045-1049, 2001.

TREVISAN, L.F.A. Estudo toxicológico $e$ investigação da atividade antilitiásica do extrato de Dianthus caryophyllus. 2012. 59f. Dissertação (Mestrado em Zootecnia) - Faculdade de Medicina Veterinária, Universidade Federal de Campina Grande, Patos, SP. 